\title{
PAEDIATRIC CYCLOPLEGIA: A NEW APPROACH
}

\author{
P. SHAH, A. S. JACKS and G. G. W. ADAMS \\ London
}

\begin{abstract}
SUMMARY
Background: Cycloplegia is a traumatic experience for most children, as guttae cyclopentolate stings on instillation into the conjunctival sac. This may result in inadequate cycloplegia, difficulty in further examination and a child who is scared of both the doctor and the ophthalmology department. Guttae proxymetacaine hydrochloride $0.5 \%$ (Ophthaine, Proparacaine) is a topical local anaesthetic that does not sting on instillation.

Methods: Eighty-eight consecutive children in the paediatric clinic were assessed. The response of the patient to previous use of cyclopentolate alone was assessed by the parents of the child using a grading scheme. The use of proxymetacaine prior to instillation of cyclopentolate was then assessed using the same grading system.

Results: Seventy per cent of the children who received cyclopentolate alone were assessed to have cried and been unhappy. Ninety-one per cent of the children who received cyclopentolate after proxymetacaine were assessed to have shown no adverse reaction to the cycloplegia and remained happy.

Conclusion: This study shows that use of proxymetacaine prior to cyclopentolate results in atraumatic cycloplegia in children. This can confer multiple benefits on the doctor-patient relationship.
\end{abstract}

A cycloplegic examination is an essential part of the paediatric ophthalmic assessment. In most cases this is achieved using cyclopentolate $1 \%$, the instillation of which causes stinging. As a consequence the child is often tearful and uncooperative, which can lead to great difficulty in examination at both that visit and subsequent visits. Ophthaine is a topical local anaesthetic that does not sting on instillation., ${ }^{1,2}$ The aim of this study was to assess whether instillation of Ophthaine prior to cyclopentolate would reduce distress to the child.

Correspondence to: Mr A. S. Jacks, OStJ, BSc (Hons), MB BS, FRCOphth, Moorfields Eye Hospital, City Road, London EC1V 2PD, UK.

\section{PATIENTS AND METHODS}

Eighty-eight consecutive children who required cycloplegic examination in an outpatient department were assessed. The median age was between 2 and 3 years old. The mean age was 4.8 years (range 3 months to 12 years). There were 42 girls and 46 boys. Of these patients $22(25 \%)$ were new patients and had never attended an ophthalmic clinic before. Sixty-six $(75 \%)$ children had received cyclopentolate alone at previous outpatient attendances. The parents of these 66 children were questioned about the reaction of the child to the instillation of cyclopentolate alone at previous visits and their response was graded (Table I). The parents were questioned before any drop instillation and were asked to grade the child's reaction themselves using the table.

In this study all 88 children were then given Ophthaine (Squibb) 30 seconds prior to the instillation of cyclopentolate $1 \%$. The response of the children to this cycloplegic regimen was recorded. Again the parents were asked to grade the reaction of the child using the grading table.

\section{RESULTS}

Eighty-eight children received Ophthaine prior to guttae cyclopentolate $1 \%$ in this study. Of these, 66 children had received guttae cyclopentolate 1\% alone at previous ophthalmic consultations and their graded responses to this are shown in Table II. Seventy per cent of children who had previously received guttae cyclopentolate $1 \%$ alone were

Table I. Subjective grading system for a child's reaction to cycloplegia $^{\text {a }}$

\begin{tabular}{cl}
\hline Grade & Response \\
\hline 1 & Happy child and no problems \\
2 & Minor grizzle lasting less than 20 seconds \\
3 & Child cried but allowed instillation of drops \\
4 & Child cried and struggled \\
5 & Failure to instil drops \\
\hline${ }^{a}$ Grading was performed by the parents
\end{tabular}

${ }^{\mathrm{a}}$ Grading was performed by the parents. 
Table II. Response of children to previous use of cyclopentolate alone

\begin{tabular}{ccc}
\hline Grade & No. of children & \% of total \\
\hline 1 & 0 & 0 \\
2 & 20 & 30 \\
3 & 29 & 44 \\
4 & 14 & 21 \\
5 & 3 & 5 \\
\hline
\end{tabular}

assessed by the parent to have cried and been unhappy (grade 2 response or more).

The response of all 88 children to cycloplegia using Ophthaine prior to guttae cyclopentolate $1 \%$ is shown in Table III. Ninety-one per cent of these children showed no adverse reaction to the cycloplegia and remained happy, as assessed by the parent. There were 22 new patients in this study having cycloplegia for the first time. No crying was observed in any of these patients.

\section{DISCUSSION}

This retrospective and prospective clinical observational study clearly shows that the use of Ophthaine prior to instillation of cyclopentolate $1 \%$ results in less traumatic cycloplegia in children. Ophthaine is a safe and effective topical anaesthetic. ${ }^{1,2}$ The efficacy of the cycloplegia was not assessed - only the reaction of the patient to the dilatation regimen. Dilatation with cyclopentolate is recognised as an adequate dilatation regimen in most patients. ${ }^{3,4}$ Alternative ways of administering cyclopentolate in order to reduce distress to the child have been tried, such as sprays. ${ }^{5}$

If the child is happy and not frightened after cycloplegia the chance of gaining a meaningful fundal examination and refraction are much improved. Any technique that does not damage the innate trust between child and doctor will have many positive effects on the initial and subsequent ophthalmic consultations. Less distress during dilatation may result in: (1) an easier examination, (2) more relaxed parents and staff, (3) less resistance at follow-up from the child, (4) a quieter clinic and (5) less upset to parents and children in the waiting room. All these may reduce the number of follow-up
Table III. Response of children to cycloplegia using Ophthaine prior to cyclopentolate

\begin{tabular}{ccc}
\hline Grade & No. of children & \% of total \\
\hline 1 & 80 & 91 \\
2 & 3 & 3 \\
3 & 1 & 1 \\
4 & 4 & 5 \\
5 & 0 & 0 \\
\hline
\end{tabular}

appointments and prevent the occasional examination under anaesthetic.

No side effects of Ophthaine were observed. However, parents should be advised that the child should not poke or rub its eyes and be warned to take care with hot liquids and food because of possible oral anaesthesia for about 30 minutes after instillation of the drops. Ophthaine has a higher incidence of contact allergy than other topical anaesthetics. ${ }^{6}$ The contact allergy is more of a problem for the clinician who may have repeated exposure to the drug. No allergic reactions were seen in any of the patients. Ophthaine takes less than 30 seconds to anaesthetise the eye $\mathrm{e}^{1,2}$ and the anaesthetic effect lasts for 10-25 minutes. ${ }^{1,2}$ This allows more than one instillation of cyclopentolate if necessary.

This technique allows painless cycloplegia and we would recommend its use, particularly at the first visit when it is easy to lose the trust of the child.

The authors have no proprietary interest in Ophthaine.

Key words: Proxymetacaine hydrochloride, Cycloplegia, Cyclopentolate, Ophthaine, Proparacaine.

\section{REFERENCES}

1. Boozan CW, Cohen IJ. Ophthaine. Am J Ophthalmol 1953;36:1619.

2. Havener WH. Ocular pharmacology, vol 5. St Louis: Mosby, 1983:77-8.

3. Gettes BC, Belmont O. Tropicamide: comparative cycloplegic effects. Arch Ophthalmol 1961;66:336-40.

4. Havener WH. Ocular pharmacology, vol 12. St Louis: Mosby, 1983:393-6.

5. Bartlett JD, Wesson MD. Efficacy of a paediatric cycloplegic administered as a spray. J Am Optom Assoc 1993;64:617-21.

6. Rosenwasser R. Complications of topical ocular anaesthetics. Int Ophthalmol Clin 1989;29:153-8. 